\title{
Acute respiratory effects of particles: mass or number?
}

T Osunsanya, G Prescott, A Seaton

\begin{abstract}
Objectives-To determine whether associations might be found, in patients with chronic airflow obstruction, between symptoms, peak flow rate (PEF), and particle mass and numbers, and to assess which measure was most closely associated with changes in health. Epidemiological studies have shown associations between particulate air pollution and cardiovascular and respiratory disease, and it has been proposed that these may be mediated by particles of $\mathrm{nm}$ size
\end{abstract} (ultrafine).

Methods-Relations were investigated between symptom scores, PEF, and bronchodilator use in 44 patients aged $\geqslant 50$ years with chronic obstructive pulmonary disease, and daily measurements of both mass of ambient particles of aerodynamic diameter less than $10 \mu \mathrm{m}\left(\mathbf{P} \mathbf{M}_{10}\right)$ and numbers of ultrafine particles $(<100 \mathrm{~nm})$, allowing for meteorological variables. Symptom scores, bronchodilator use, and PEF were recorded daily for 3 months. Counts of ultrafine particles were made by the TSI model 3934 scanning mobility particle sizer (SMPS) and $\mathbf{P M}_{10}$ measurements by the tapered element oscillating microbalance (TEOM).

Results-Ultrafine particle counts indoors and outdoors were significantly correlated, those indoors being about half of those outdoors. No associations were found between actual PEF and $\mathbf{P M} M_{10}$ or ultrafine particles. However, there was a $19 \%$ increase in the rate of $10 \%$ decrements in daytime PEF with increases in $P M_{10}$ from 10 to $20 \mu \mathrm{g} / \mathrm{m}^{3}$ which was of borderline significance $(p=0.05)$. A change in $\mathbf{P M}_{10}$ from 10 to $20 \mu \mathrm{g} / \mathrm{m}^{3}$ was significantly associated with a $14 \%$ increase in the rate of high scores of shortness of breath $(p=0.003)$. A similar change in $\mathbf{P M}_{10}$ as a moving average of the same day and 2 previous days was associated with a $31 \%$ increase in the rate of high scores for cough $(p=0.02)$. Cough symptoms were also associated with lower temperatures $(p=0.02)$. Higher use of medicines was also associated with higher $\mathbf{P M}_{10}$, but the increases were very small in clinical terms.

Conclusions-Evidence was not found to support the hypothesis that the component of particulate pollution responsible for effects on respiratory symptoms or function resides in the fraction below 100 nm diameter. The consistent associations between symptoms and $\mathbf{P} \mathbf{M}_{10}$ suggest that a contribution of the coarser fraction should not be dismissed. Further studies will be needed before the conclusions of this specific project may be generalised. (Occup Environ Med 2001;58:154-159)

Keywords: air pollution; ultrafine particles; chronic obstructive lung disease

There is evidence that particulate air pollution, even at the relatively low concentrations prevalent currently in United Kingdom cities, may be responsible for adverse effects on health. ${ }^{1}$ The main associations seem to be with respiratory and cardiac effects, particularly in older people, and it seems likely that the effect of particles is to cause exacerbation of already existing disease in vulnerable people. As the effects are acute, occur at relatively low concentrations, and are associated with particles of apparently innocuous composition (largely carbon and ammonium sulphate and nitrate), it has been necessary to consider a novel pathogenic mechanism. One that has been proposed is that the pathogenicity of the particles is based not on the mass inhaled but rather on their numbers, and thus the surface area available to react with epithelial and inflammatory cells in the lung. ${ }^{2}$

This hypothesis was based partly on the finding that rats exposed to very small particles have markedly more pulmonary inflammation than do rats exposed to the same mass of material of larger size, ${ }^{34}$ and partly on knowledge that the particles derived from combustion characteristically found in urban air are predominantly in the ultrafine $(<100 \mathrm{~nm})$ size range. Subsequent work has suggested that such particles may exert adverse biological effects by release of toxic free radicals from their surfaces. 5

Control of the problem of adverse health effects of particulate pollution depends on reduction of the exposures of populations to the toxic components of the pollutant. This is currently effected by control of the fraction of particles less than $10 \mu \mathrm{m}$ in aerodynamic diameter $\left(\mathrm{PM}_{10}\right)$. However, this metric may be dominated by larger, wind blown particles in the size range $1-10 \mu \mathrm{m}$, rather than by the much more numerous ultrafine particles (UFP). In theory therefore, if the ultrafine hypothesis is correct, $\mathrm{PM}_{10}$ may in some circumstances seriously misrepresent the toxicity of the pollutant. It is thus desirable to attempt to determine a metric that better represents the toxic component, so that ultimately this may be used as the basis for a standard for 
monitoring pollution control. We here report a study in which we have investigated associations between health effects in a panel of vulnerable people and both $\mathrm{PM}_{10}$ and measurement of the number of particles below $100 \mathrm{~nm}$ diameter.

\section{Subjects and methods}

METHODS

Meteorological data

A Skyeminimet SDL2990 weather station installed on the roof of the department's pollution laboratory located in central Aberdeen provided continuous data on temperature, relative humidity, wind speed, and wind direction. This was stored on a spreadsheet and later converted to values for daily mean, minimum, and maximum measurements. Wind direction was summarised as the number of days with wind from directions falling in each of eight sectors.

\section{Air pollution data}

$\mathrm{PM}_{10}$ measurements were obtained from a Rupprecht and Patashnick tapered element oscillating microbalance (TEOM) ambient particulate monitor of Aberdeen City Council. This was also located at a background site in the city centre, about 2 miles from our laboratory. Data were compressed to daily 24 hour mean, minimum, and maximum values. A TSI model 3934 scanning mobility particle sizer (SMPS) was used for sizing and counting aerosols of less than a $\mu \mathrm{m}$. The SMPS system comprises a TSI model 3071A electrostatic classifier and a model 3022A condensation particle counter. Hourly samples were made in two scans, each sample lasting for 5 minutes at an automatically regulated flow rate of $5 \mathrm{l} / \mathrm{min}$. Data were exported onto spreadsheets.

As the patients spent much time indoors, in a separate exercise a comparison of particle counts was made inside and outside the laboratory with windows closed. Only background counts were considered as indoor counts vary with combustion of domestic fuels. Seventy nine concurrent measurements of indoor and outdoor counts were run for 2 months of this 3 month study.

\section{SUBJECTS}

Approval for the study was obtained from the joint ethics committee of the Grampian Health Board and the University of Aberdeen. Patients were recruited from chest clinics at the Aberdeen Royal Hospitals; 44 gave written consent to participate in the study. They had airflow obstruction associated with either asthma or chronic obstructive pulmonary disease and answered positively when asked if the weather affected their chest. All were 50 years or above in age and resident within 5 miles of the air monitoring sites. They completed a questionnaire inquiring about their house, general indoor and outdoor activities, and exposure to dusts, fumes, and cigarette smoke. They were then asked to keep a daily diary of chest symptoms, use of inhalers, and twice daily peak expiratory flow (PEF) for 3 months.
The Ferraris Medical Poketpeak peak flow meter was used, recording between 90 and 710 $1 / \mathrm{min}$. Each subject was instructed in its use and asked to record the best of three blows twice a day. Scores for cough and shortness of breath were graded once daily on a 6 point scale $0-5,0$ for no symptoms at all and 5 for the worst possible symptoms. Total number of puffs on an inhaler was recorded. Night time scores were recorded as were those the next morning at about 0800 before the use of any drugs. Daytime symptoms were recorded at about 2000 .

ANALYSIS OF DATA

All the measurements made were entered on spreadsheets. Symptom scores for cough and shortness of breath were further categorised as high if scored as 3 or higher and low if scored as 2 or lower. Presence or absence of any symptoms was not chosen as an outcome because most subjects reported some symptoms each day. We took two approaches when looking at the influence of particles on PEF. Firstly the actual PEF value for each person was examined. Secondly we analysed the presence or absence of a $10 \%$ decrement in PEF on each day relative to that person's median PEF, in view of the suggestion of Hoek et $a l^{6}$ that this may be a more clinically important indicator than PEF itself. The percentage decrement was calculated as 100 (daily PEF-median PEF)/ median PEF. These outcomes, whether continuous or binary, were examined relative to the mean meteorological and pollution measurements on the same day and as a 3 day moving average.

When examining the actual values of PEF for each person the Cochrane-Orcutt regression procedure with the prais function within Stata was selected, ${ }^{7}$ and adjustments were made for first order autocorrelation. ${ }^{8}$ Durbin Watson tests were used to check whether these adjustments for the high correlation between sequential measurements were sufficient. This regression took account of the fact that there were many observations on the same subject and resulted in a regression equation for today's health measurement including potentially influential environmental factors, adjustment for the previous day's health measurement, and a subject specific component. Generalised estimating equations were used to examine the binary outcomes for the presence of a $10 \%$ decrement in PEF and the presence of high levels of symptoms of cough or shortness of breath. ${ }^{9}$ The xtgee function within Stata was used as this was designed for panel data and can be set to adjust for first order serial association. Significance was taken to be at the conventional 5\% level. No adjustment was made for multiple testing, and the increased probability of spurious associations is acknowledged in the discussion.

\section{Results}

Of the 44 who agreed to take part, 27 had complete data for PEF, symptoms, and medicine use. Eight others had more than $80 \%$ of required data, and six had some usable data, 


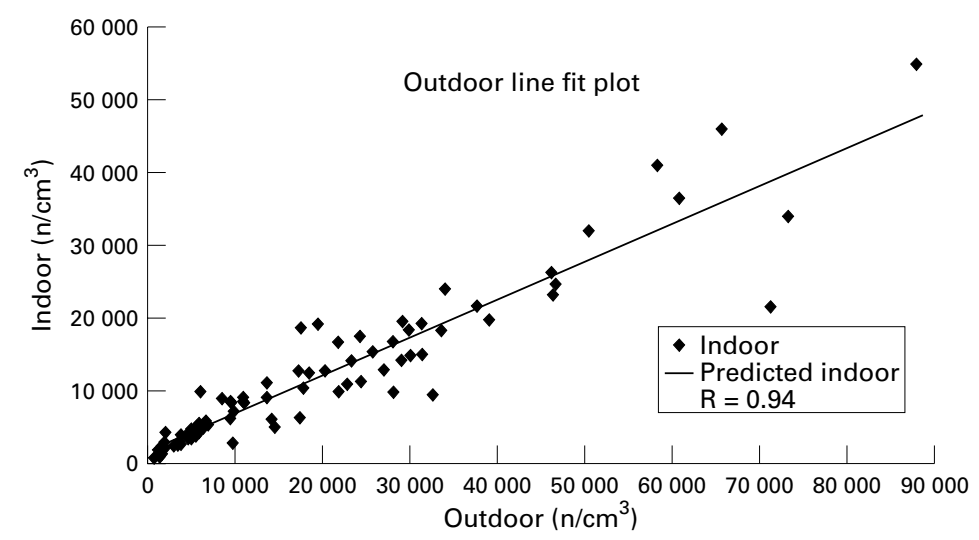

Figure 1 Best line fit plot for outdoor versus indoor ultrafine particle counts over 2 months.

leaving three that provided none of value. The age range of patients was between 50 and 79 years and was normally distributed (mean (SD) $66.45(8.23)$ ). There were 25 men $(57 \%)$ and 19 women $(43 \%), 38$ (86\%) being non-smokers, nine $(20 \%)$ of them lifetime non-smokers.

\section{RELATION BETWEEN OUTDOOR AND INDOOR}

ULTRAFINE PARTICLE COUNTS

There was a highly significant relation between outdoor and indoor ultrafine particle counts $(\mathrm{p}<0.0001$, fig 1$)$, the indoor counts being over half those of the outdoor counts. The linear regression equation was:

\section{Indoor count $($ particles $/ \mathrm{ml})=$ $0.527 \times$ outdoor count +1468 .}

ASSOCIATIONS BETWEEN PARTICLE MEASURES AND HEALTH INDICES

Particle measurements

Because of some loss of data owing to equipment malfunction over Christmas, there were 78 valid daily counts of ultrafine particles and 85 of $\mathrm{PM}_{10}$ over the 90 day measurement period. The distribution of pollution measurements was highly positively skewed (table 1), so natural logs of these were taken before they were considered in regression models.

Interrelations of particle measures

The two measures of particulate pollution were significantly correlated: $\mathrm{PM}_{10}$ to ultrafine particle numbers $(r=0.49)$.

\section{Meteorological measurements}

On every day of the 90 day period records were available for temperature $\left({ }^{\circ} \mathrm{C}\right)$, relative humidity $(\mathrm{RH} \%)$, wind speed $(\mathrm{m} / \mathrm{s})$, and wind direction in degrees. Wind speed was positively skewed, but temperature and humidity were

Table 1 Summary statistics of air pollution variables

\begin{tabular}{|c|c|c|c|c|}
\hline Particles & $\begin{array}{l}\text { Valid } \\
\text { measurements } \\
\text { (n) }\end{array}$ & Median & Min & $\operatorname{Max}$ \\
\hline \multicolumn{5}{|l|}{ Same day: } \\
\hline $\operatorname{UFP}\left(\mathrm{n} / \mathrm{cm}^{3}\right)$ & 78 & 10241 & 740 & 60636 \\
\hline $\mathrm{PM}_{10}\left(\mu \mathrm{g} / \mathrm{m}^{3}\right)$ & 85 & 13 & 6 & 34 \\
\hline \multicolumn{5}{|c|}{3 Day moving average: } \\
\hline $\operatorname{UFP}\left(\mathrm{n} / \mathrm{cm}^{3}\right)$ & 72 & 10379 & 1564 & 45932 \\
\hline $\mathrm{PM}_{10}\left(\mu \mathrm{g} / \mathrm{m}^{3}\right)$ & 81 & 14 & 8 & 30 \\
\hline
\end{tabular}

Table 2 Summary statistics of meteorological variables

\begin{tabular}{|c|c|c|c|}
\hline & & Mean & $S D$ \\
\hline \multicolumn{4}{|c|}{ Temperature $\left({ }^{\circ} \mathrm{C}\right)$ : } \\
\hline Min & & 2.78 & 2.77 \\
\hline Mean & & 4.85 & 2.72 \\
\hline $\operatorname{Max}$ & & 7.07 & 3.01 \\
\hline \multicolumn{4}{|c|}{ Humidity (RH \%): } \\
\hline Min & & 69.2 & 9.8 \\
\hline Mean & & 80.5 & 7.1 \\
\hline Max & & 90.7 & 5.2 \\
\hline & Median & Min & $\operatorname{Max}$ \\
\hline \multicolumn{4}{|c|}{ Wind speed $(\mathrm{m} / \mathrm{s})$ : } \\
\hline Min & 0.56 & 0.00 & 2.35 \\
\hline Mean & 1.26 & 0.06 & 4.73 \\
\hline $\operatorname{Max}$ & 1.90 & 0.67 & 7.89 \\
\hline \multirow{2}{*}{\multicolumn{4}{|c|}{ Wind direction (coming from): }} \\
\hline & & & \\
\hline N/NE & & 2 & 2.2 \\
\hline $\mathrm{NE} / \mathrm{E}$ & & 1 & 1.1 \\
\hline $\mathrm{E} / \mathrm{SE}$ & & 6 & 6.7 \\
\hline $\mathrm{SE} / \mathrm{S}$ & & 23 & 25.6 \\
\hline S/SW & & 33 & 36.7 \\
\hline SW/W & & 11 & 12.2 \\
\hline $\mathrm{W} / \mathrm{NW}$ & & 11 & 12.2 \\
\hline NW/N & & 3 & 3.3 \\
\hline
\end{tabular}

close to normal in distribution. Average results for wind speed, temperature, humidity, and the percentage of days with each wind direction are shown in table 2 . Wind was most often from the south south west sector. Of the meteorological variables, only wind speed varied with wind direction and was greatest on the few days that the wind was from the north east.

\section{Health indices}

The mean PEF measurements over all subjects were normally distributed with values of 264 $1 / \mathrm{min}$ in the morning and $267 \mathrm{1} / \mathrm{min}$ at night (table 3 ). The mean proportion (of those with available data on that day) who had high levels of symptoms was $50 \%$ (range $32 \%$ to $65 \%$ ) for shortness of breath and $31 \%$ (range $15 \%$ to $47 \%$ ) for cough. There were positive correlations between mean humidity and both pollution measures of about $0.4 . \mathrm{PM}_{10}$ was positively correlated with mean and maximum temperature $(r=0.26)$.

The simple correlations between the original scores of cough and shortness of breath and use of medicine were all positive and greater than 0.5 . There were the expected negative associations between both daytime and night time PEF and symptom scores and use of medication $(p<0.001)$. No significant correlations were found between PEF and any of the particulate or meteorological measurements. Wind direction was not associated with any of the health outcomes. Thirty five subjects provided at least $80 \%$ of the requested data and so were included in the analysis of PEF. There were great differences between people in both median PEF and the range over the 90 days of follow up.

The results displayed in tables 4-6 are odds ratios for changes of 1 unit of measurementfor example, $1^{\circ} \mathrm{C}$ in temperature, $1 \mathrm{~m} / \mathrm{s}$ in wind speed, $1 \%$ in relative humidity, and a change of 1 in the $\log$ of $\mathrm{PM}_{10}$. This is equivalent to a change from 6 to $16 \mu \mathrm{g} / \mathrm{m}^{3}$ or 10 to $27 \mu \mathrm{g} / \mathrm{m}^{3}$. Over the 90 days the average temperature was $4.8^{\circ} \mathrm{C}$, humidity was $81 \%$, and the median 
Table 3 Mean peak flow results

\begin{tabular}{lllll}
\hline & Mean & SD & Min & Max \\
\hline PEF-day (1/min, mean) & 264 & 5 & 253 & 277 \\
PEF-night (1/min, mean) & 267 & 5 & 256 & 277 \\
\hline
\end{tabular}

Table 4 Model for $10 \%$ decrements in day time peak flow rate

\begin{tabular}{llll}
\hline & $p$ Value & $\begin{array}{l}\text { OR for change of one } \\
\text { unit of measurement }\end{array}$ & 95\% CIs \\
\hline Mean temperature $\left({ }^{\circ} \mathrm{C}\right)$ & 0.18 & 0.97 & 0.928 to 1.014 \\
Mean wind speed $(\mathrm{m} / \mathrm{s})$ & 0.10 & 1.097 & 0.981 to 1.225 \\
Mean humidity (\%) & 0.44 & 1.006 & 0.991 to 1.020 \\
Log $\mathrm{PM}_{10}$ & 0.05 & 1.284 & 0.996 to 1.656 \\
\hline
\end{tabular}

Table 5 Model for high cough score

\begin{tabular}{llll}
\hline & $p$ Value & $\begin{array}{l}\text { OR for change of one } \\
\text { unit of measurement }\end{array}$ & 95\% CIs \\
\hline Mean temperature $\left({ }^{\circ} \mathrm{C}\right)$ & 0.02 & 0.965 & 0.936 to 1.994 \\
Mean wind speed $(\mathrm{m} / \mathrm{s})$ & 0.05 & 1.078 & 0.999 to 1.164 \\
Mean humidity $(\%)$ & 0.41 & 0.996 & 0.987 to 1.005 \\
$\log 3$ day $\mathrm{PM}_{10}$ & 0.02 & 1.470 & 1.066 to 2.028 \\
\hline
\end{tabular}

Table 6 Model for high breathlessness score

\begin{tabular}{llll}
\hline & p Value & $\begin{array}{l}\text { OR for change of one } \\
\text { unit of measurement }\end{array}$ & 95\% CIs \\
\hline Mean temperature $\left({ }^{\circ} \mathrm{C}\right)$ & 0.16 & 0.983 & 0.959 to 1.007 \\
Mean wind speed $(\mathrm{m} / \mathrm{s})$ & 0.90 & 1.004 & 0.940 to 1.011 \\
Mean humidity $(\%)$ & 0.30 & 1.004 & 0.997 to 1.011 \\
Log $\mathrm{PM}_{10}$ & 0.003 & 1.214 & 1.068 to 1.380 \\
\hline
\end{tabular}

wind speed was $1.26 \mathrm{~m} / \mathrm{s}$. When interpreting the odds ratios for changes in $\mathrm{PM}_{10}$ we have kept the values of the potential confounders fixed at these average daily values.

In regression models for lung function, allowing for first order autocorrelation, none of the meteorological variables was associated with daytime or night time PEF. No significant associations were found between daytime or night time PEF and the two measures of pollution after adjustment for confounders.
Selected results for PEF and symptoms are shown in figure 2. No association was found between ultrafine particles and decrements of $10 \%$ in daytime or night time PEF. However, associations were found between the decrements of $10 \%$ in daytime PEF and increasing values of $\log \mathrm{PM}_{10}$ on the same day which were of borderline significance after adjusting for mean temperature, wind speed, humidity, and serial association. The odds ratio for a change from 10 to $20 \mu \mathrm{g} / \mathrm{m}^{3}$ was 1.19 (95\% confidence interval (95\% CI) 1.00 to 1.42$)$. On an average day with a $\mathrm{PM}_{10}$ of $10 \mu \mathrm{g} / \mathrm{m}^{3}$ the rate of $10 \%$ decrement in daytime PEF would be $15 \%$ of the people. At $\mathrm{PM}_{10}$ of $20 \mu \mathrm{g} / \mathrm{m}^{3}$ it would be $18 \%$ and at $30 \mu \mathrm{g} / \mathrm{m}^{3}$ it would be $19 \%$.

We used the same generalised estimation equation approach to look for the presence of high levels of symptoms $(\geqslant 3)$ in 35 subjects. No significant associations between symptoms and ultrafine particles were found. High levels of symptoms of cough were significantly associated with lower mean temperatures $(p=0.02)$ and higher log of $\mathrm{PM}_{10}$ over the previous 3 days $(p=0.02)$ after adjusting for autocorrelation, mean wind speed, and humidity (table 5). The odds ratio shown is for a 1 unit change in log of $\mathrm{PM}_{10}$ as a 3 day average. The odds ratio for a change of 0.7 units, equivalent to a change of 10 to $20 \mu \mathrm{g} / \mathrm{m}^{3}$, was 1.31 (1.05 to 1.63). On an average day with a $\mathrm{PM}_{10}$ as a 3 day average of $10 \mu \mathrm{g} / \mathrm{m}^{3}$ the rate of high levels of symptoms of cough would be $28 \%$. If this measure of $\mathrm{PM}_{10}$ was $20 \mu \mathrm{g} / \mathrm{m}^{3}$ it would be $34 \%$, and at $30 \mu \mathrm{g} / \mathrm{m}^{3}$ it would be $38 \%$.

There was a significantly positive association between high levels of symptoms of shortness of breath and log same day $\mathrm{PM}_{10}(\mathrm{p}=0.003)$. This association remained significant after adjusting for wind speed, humidity, and temperature (table 6). The odds ratio shown is for a 1 unit change in log of $\mathrm{PM}_{10}$ over the previous 3 days. The odds ratio for a change of 0.7

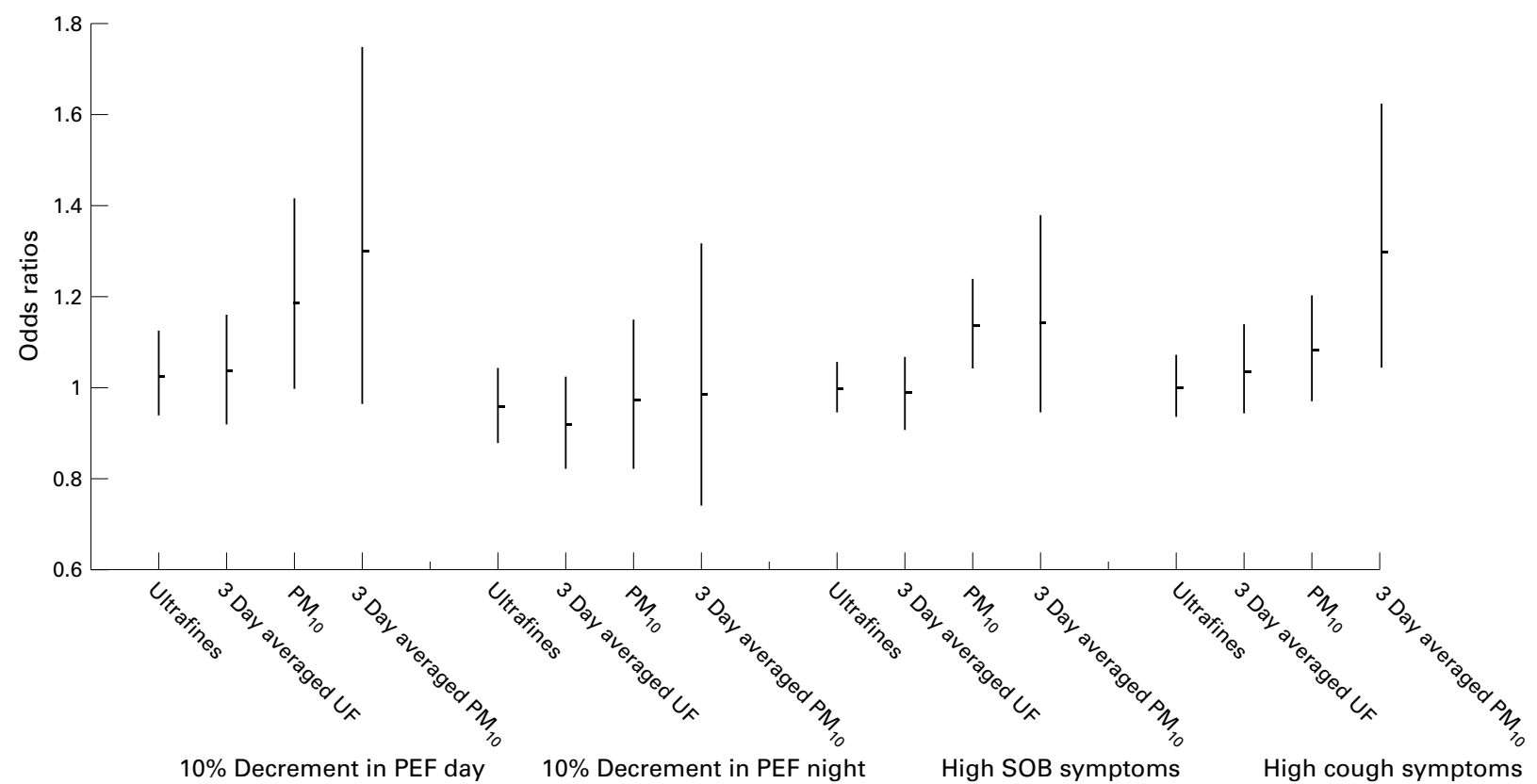

Figure 2 Results from regression model, allowing for wind speed, humidity, temperature, and serial association, showing odds ratios for changes in PM ${ }_{10}$ from $10-20 \mu \mathrm{g} / \mathrm{m}^{3}$ or in ultrafine counts from $10000-20000 / \mathrm{cm}^{3}$. 
Table 7 Model for use of medication

\begin{tabular}{lccr}
\hline & \multicolumn{3}{c}{$\begin{array}{l}\text { Estimate of increase in } \\
\text { medication } \\
\text { increase in } \\
\text { measurement }\end{array}$} \\
\hline Mean temperature $\left({ }^{\circ} \mathrm{C}\right)$ & 0.11 & -0.018 & $95 \% \mathrm{CIs}$ \\
Mean wind speed $(\mathrm{m} / \mathrm{s})$ & 0.11 & 0.048 & -0.039 to 0.004 \\
Mean humidity $(\%)$ & 0.14 & 0.005 & -0.011 to0.107 \\
Log $\mathrm{PM}_{10}$ & 0.04 & 0.118 & -0.002 to0.011 \\
Constant & $<0.001$ & 3.667 & 0.005 to 0.232 \\
\hline
\end{tabular}

units, equivalent to a change 10 to $20 \mu \mathrm{g} / \mathrm{m}^{3}$, was 1.14 (1.05 to 1.25$)$. On an average day with a $\mathrm{PM}_{10}$ over the 3 previous days of 10 $\mu \mathrm{g} / \mathrm{m}^{3}$ the rate of high levels of symptoms of shortness of breath would be $47 \%$. If this measure of $\mathrm{PM}_{10}$ was $20 \mu \mathrm{g} / \mathrm{m}^{3}$ it would be $50 \%$, and at $30 \mu \mathrm{g} / \mathrm{m}^{3}$ it would be $52 \%$.

Medicine use was treated as a continuous measure. The values in the model shown in table 7 are estimates of the mean change in use of medicine for 1 unit change in the relevant factor. There was an association between high use of medicine and higher same day $\mathrm{PM}_{10}$ $(p=0.04)$ which was significant after adjusting for autocorrelation, mean temperature, wind speed, and humidity. The size of this effect was very small in clinical terms. An increase of 1 unit in $\log \mathrm{PM}_{10}$ was associated with a 0.12 increase in the dose of medicine used. On an average day, use increased from 4.30 doses to 4.43 doses as $\mathrm{PM}_{10}$ increased from 10 to 30 $\mu \mathrm{g} / \mathrm{m}^{3}$. The estimates for the model including $\log \mathrm{PM}_{10}$, mean temperature, wind speed, and humidity showed a significant association between increasing $\log \mathrm{PM}_{10}$ and the higher use of medication.

\section{Discussion}

Control of particulate air pollution, unlike that of other pollutants, is based on a physical rather than chemical measurement. The particles as measured may therefore be of a wide range of different compositions, and contain both chemicals and biological matter. Nevertheless, epidemiological studies have shown similar associations between adverse health effects and particulate pollution, wherever it is measured, whatever the main sources, and whether it has been measured as $\mathrm{PM}_{10}$ or black smoke, which represents a smaller size range. This suggests that there may be a common factor in particles responsible for adverse effects. Theoretical arguments and experimental studies suggest that much of the toxic component may lie in the fraction below about $1 \mu \mathrm{m}$, and most probably in particles of $<100 \mathrm{~nm}$ diameter. At present there are relatively few data allowing an epidemiological test of this hypothesis, and time series studies comparing $\mathrm{PM}_{10}$ with $\mathrm{PM}_{2.5}$ have so far been unable to separate their effects as the two measures are highly correlated. The work reported here suggests that, whatever the effects of ultrafine particles, the contribution of particle mass (and by implication, the larger particles) towards respiratory ill health cannot be dismissed.

Few studies have previously looked at counts of particles relative to health. In a cohort of asthmatic children, whose main source of par- ticulate air pollution was motor vehicle exhaust from freeways, the number of ultrafine particles was found to be no more strongly associated with variations in PEF than was $\mathrm{PM}_{10}$ or black smoke. ${ }^{10}$ By contrast, the same group of authors found a stronger effect of particle numbers in asthmatic children in two other studies, ${ }^{11}{ }^{12}$ and a German study has shown the ultrafine fraction to be more strongly associated with decrease in lung function in adult asthmatic patients than was $\mathrm{PM}_{10} \cdot{ }^{13}$ We found a very strong correlation between indoor and outdoor ultrafine particles with those indoors being half of these outdoors, so any health influences will be hard for susceptible people to avoid.

Our study shows some of the problems in such research, particularly relating to the difficulty of differentiating between the effects of different but intercorrelated particle measures and confounding weather variables. There is, however, some consistency with these other studies. ${ }^{14} 15$ The associations we did find were in the anticipated direction, both symptoms and peak flow deteriorating as pollution increased. No association was statistically strong, reflecting small numbers and relatively little individual variation in the indices we measured. It should also be noted that the levels of pollution were very low in historic terms $-\mathrm{PM}_{10}$ did not rise higher than $40 \mu \mathrm{g} / \mathrm{m}^{3}$-in other words no episode of pollution occurred over the period of the study, and it is perhaps remarkable that effects were found at such concentrations. We think that the strongest results of our study are those from the regression models, as multiple simple correlations will be affected by chance positive findings and the confounding effects of weather. We can therefore summarise our positive findings as having shown two main associations, one between high scores of shortness of breath and same day $\mathrm{PM}_{10}$, and the other between high scores of cough and 3 day $\mathrm{PM}_{10}$. The association with $\mathrm{PM}_{10}$ was little influenced by weather confounders. The other association between $10 \%$ decrements in daytime PEF and same day $\mathrm{PM}_{10}$ did not quite reach conventional levels of significance but was consistent with the other findings.

The power within this study was limited by few patients who returned all the required data and by the small range of particulate measurements. Time series studies only slightly bigger than this have been reported before, but these had greater power because of the greater range of $\mathrm{PM}_{10}$ linked to nearby industrial processes. There is also the possibility in our study of spurious associations because there were four measures of pollution and seven health outcomes. We might expect one or two significant associations even if there were no real effects. However, this is offset by the consistency in the size and direction of the same day and 3 day average $\mathrm{PM}_{10}$ measures for each of the outcomes, although not all were significant, and the consistency in the direction of the associations across four of the health outcomes.

It is perhaps going beyond what the data allow to speculate as to whether these results are biologically plausible. However, it is conceivable 
that larger particles, together with weather, might affect the airways primarily and that mass may be important in this respect. The original ultrafine hypothesis was proposed as an explanation of downstream effects of low concentrations of particulate pollution on the cardiovascular system, and it remains possible that such effects are explicable by alveolar inflammation affecting blood rheology. However, in our direct test of particulate pollution on the blood, we also showed effects of $\mathrm{PM}_{10} \cdot{ }^{16}$ Whatever the explanation, it seems clear that it would be premature to replace the measurement of $\mathrm{PM}_{10}$ with that of a finer fraction on what are to date largely theoretical grounds. Longer time series studies and larger studies such as this of panels of susceptible subjects will be necessary. Also, it is highly desirable to develop means of estimating exposures of people to the finer fractions of particulate pollution to increase the ability of these studies to pick up what seem to be weak effects in the pollution conditions present currently in the United Kingdom. ${ }^{17}{ }^{18}$

This study was supported by a grant from the United Kingdom Department of Health and an equipment grant from Aberdeen University. We are grateful to Ferraris Medical for their gift of peak flow meters. We are also particularly grateful for the helpful comments of the anonymous referees on an earlier draft of this paper.

1 Anderson HR, Limb ES, Bland JM, et al. Health effects of an air pollution episode in London, December 1991. Thorax 1995;50:1188-93.

2 Seaton A, MacNee W, Donaldson K, et al. Particulate air pollution and acute health effects. Lancet 1995;345:176-8.

3 Ferin J, Oberdörster G, Penney DP. Pulmonary retention of ultrafine and fine particles in rats. Am f Respir Cell Mol Biol 1992;6:535-42.
4 Oberdörster G, Gelein R, Ferin J, et al. Association of particulate air pollution and acute mortality: involvement of ultrafine particles? Inhal Toxicol 1995;7:111-24.

5 Stone V, Shaw J, Brown DM, et al. The role of oxidative inhibitory effect of ultrafine carbon black on epithelial cell function. Toxicology in Vitro 1998;12:649-59.

6 Hoek G, Dockery DW, Pope A, et al. Association between $\mathrm{PM}_{10}$ and peak expiratory rates in children: reanalysis of data from five panel studies. Eur Respir F 1998;11:1307-11.

7 Cochrane D, Orcutt GH. Application of least squares regression to relationships containing autocorrelated regression terms. Fournal of the American Statistical Association 1949;44:32-61.

8 Durbin J, Watson GS. Testing for serial correlation in leastsquares regression. Biometrika 1950;37:409-28, 1951;38: 159-78.

9 Liang KY, Zeger SL. Longitudinal data analysis using generalised linear models. Biometrika 1986;73:13-23.

10 Pekkanen J, Timonen KL, Ruuskanen J, et al. Effects of fine and ultrafine particles in urban air on peak expiratory flow among children with asthmatic symptoms. Environ Res 1997;74:24-33.

11 Tiittanen P, Timonen KL,Ruuskanen J, et al. Fine particulate air pollution, resuspended road dust and respiratory health among symptomatic children. Eur Respir f 1999;13: 266-73.

12 Timonen KL, Pekkanen J. Air pollution and respiratory health among children with asthmatic or cough symptoms. Am 7 Respir Crit Care Med 1997;156:546-52.

13 Peters A, Wichmann HE, Tuch T, et al. Respiratory effects are associated with the number of ultrafine particles. $A m \mathcal{F}$ Respir Crit Care Med 1997;155:1376-83.

14 Pope CA, Dockery DW. Acute health effects of $\mathrm{PM}_{10}$ pollution on symptomatic and asymptomatic children. Am Rev Respir Dis 1992;145:1123-8.

15 Pope CA, Dockery DW, Spengler JD, et al. Respiratory health and $\mathrm{PM}_{10}$ pollution: a daily time series analysis. $\mathrm{Am}$ Rev Respir Dis 1991;144:668-74.

16 Seaton A, Soutar A, Crawford V, et al. Haematological effects of particulate air pollution. Thorax 1999;54:102732.

17 Watt M, Godden D, Cherrie J, et al. Individual exposure to particulate air pollution and its relevance to thresholds for health effects: a study of traffic wardens. Occup Environ Med 1995;52:790-2.

18 Carrothers TJ, Evans JS. Assessing the impact of differential measurement error on estimates of fine particle mortality. $\mathcal{F}$ Air Waste Manag Assoc 2000;50:65-74.

\section{Correspondence and editorials}

Occupational and Environmental Medicine welcomes correspondence relating to any of the material appearing in the journal. Results from preliminary or small scale studies may also be published in the correspondence column if this seems appropriate. Letters should be not more than 500 words in length and contain a minimum of references. Tables and figures should be kept to an absolute minimum. Letters are accepted on the understanding that they be subject to editorial revision and shortening.

The journal also publishes editorials which are normally specially commissioned. The Editor welcomes suggestions regarding suitable topics; those wishing to submit an editorial, however, should do so only after discussion with the Editor. 